\title{
0 anti-Taylor: sobre a invenção de um método para co-governar instituições de saúde produzindo liberdade e compromisso
}

\author{
An anti-Taylorist approach for establishing \\ a co-governance model for health care institutions \\ in order to produce freedom and commitment
}

Gastão Wagner de Sousa Campos 1

\footnotetext{
1 Departamento de Medicina Preventiva e Social da Faculdade de Ciências Médicas, Universidade Estadual de Campinas. Rua Américo de Campos 93, Cidade Universitária, 13083-040, Campinas, SP gastao@mpc.com.br
}

Abstract This paper describes a new health care management method. A triangular confrontati on system was constructed, based on a theoretical review, empirical facts observed from health services, and the researcher's knowledge, jointly analyzed. This new management model was termed "health-team-focused collegi ate management", entailing several original organizational concepts: production unity, matrix-based reference team, coll egi ate management system, co-governance, and product/production interface.

Key words Health Management; Public Management; Democratic Management

Resumo Descrição de um novo Método para Co-governar Organizações de Saúde, considerando-se tanto os objeti vos primários destas institui ções (a própria produção de saúde) quanto outros, secundários, ligados à função de assegurar sobrevivência e realização profissional aos seus trabalhadores. O novo Método é denominado de Gestão Colegiada centrada em Equi pes de Saúde. Esta construção resul tou de um sistema de confrontação triangular entre determinado corpo de Teorias, dados empíricos observados no Si stema Ú nico de Saúde e a experiência e conhecimentos do próprio pesqui sador. São descritos al guns dispositivos organizacionais origi nais (novos ou reconcei tual izados), entre el es: Unidade de Produção; Equi pe de Referência e Trabalho de apoio Matricial; Sistema de Gestão Colegiada; Co-governo; Supervisão Matricial; eo de Produto/Obra.

Palavras-chave Administração em Saúde; Administração Pública; Gestão Democrática 


\section{Considerações metodológicas}

Este trabalho objetiva descrever um novo Modelo de Gestão para Sistemas e Estabelecimentos de saúde. Poder-se-ia denominar este novo método de Gestão Colegiada, ou de Gestão Democrática ou de Gestão Colegiada centrada em Equipes de Saúde.

Devido ao âmbito restrito desta apresentação não será desenvolvida uma nova Teoria que fundamentasse o novo M étodo sugerido, isto seria tarefa para trabalho de maior fôlego, conforme seria o caso de uma pesquisa, já em andamento, de livre-docência.

A utopia da democracia direta e alguns modos práticos para concretizá-la

Nada como desafios impostos pela vida (mundo empírico) para estimular Sujeitos a reconhecerem pontos de quebra ou de contradição em suas Teorias. Se a Teoria Geral da Administração jamais pretendeu, de fato, democratizar Organizações; o marxismo, por seu turno, apesar das críticas à concentração de poder burocrático, político e econômico, nunca deu conta, na prática, da Democracia em Instituições. Logo de início, os principais dirigentes da Revolução Soviética adotaram o taylorismo como o Método científico supostamente adequado para organizar fábricas, empresas e hospitais Rago \& Moreira (1984). Sem dúvida, esta decisão contribuiu, em alguma medida, para a rápida e avassaladora dominância da burocracia em múltiplas dimensões da vida na extinta URSS. No limite, pode-se verificar que algumas variantes do marxismo produziram, já como preparação ou desdobramento dos movimentos libertários dos anos sessenta, críticas à burocratização e à concentração de poder em instituições, nunca chegando, no entanto, a produzir, de maneira sistemática, Métodos e Técnicas organizacionais alternativos à lógica criada por Taylor (1960) e Fayol (1960) - Braverman (1981), Gorz (1982), Offe (1989), Tragtemberg (1972, 1980).

No Brasil, dentro do processo de implantação do Sistema Único de Saúde (SUS), há inúmeras experiências voltadas para ampliar a democracia em instituições de saúde. A descentralização de poder para os municípios (processo de municipalização) e a instalação de Conselhos e Conferências de Saúde, com maioria de usuários, estão entre os principais dispositivos sugeridos pelo SUS para alterar o funcionamento burocrático do Estado. Ainda que para lograr algum grau de participação popular ou de municipalização haja dificuldades imensas, estas medidas parecem insuficientes tanto para alcançar os objetivos do SUS, quanto para diminuir o alto grau de alienação que se constata entre maioria dos trabal hadores.

Inventar um modelo de gestão que respondesse a uma série de exigências do próprio modelo de atenção sugerido pelo SUS é, portanto, um desafio em aberto. Construir uma alternativa operacional ao método taylorista de gestão foi o desafio assumido por este pesquisador. Um sistema de gestão que assegurasse tanto a produção qualificada de saúde, quanto garantisse a própria sobrevivência do Sistema e a realização de seus trabalhadores.

Há um grande desenvolvimento teórico e operacional sobre métodos e técnicas de Planejamento em Saúde - Testa (1993). No entanto, o Planejamento não esgota a maioria das tarefas de um sistema de gestão. Um bom método de planejamento, por si só, não dispensa um bom sistema de gerência para que, inclusive, seja garantida a real implantação do plano elaborado.

Há ainda outros desafios mais específicos mas nem por isto menos importantes para aqueles interessados em assegurar as principais diretrizes do SUS. Recomendam-se programas sanitários assentados em trabalho interdisciplinar (Rotelli, 1990). No entanto, as organizações de saú de são todas recortadas por outra lógica: departamentos, divisões e seções montados segundo profissões: corpo clínico de médicos, serviço de enfermagem, de assistência social, nutrição, etc.

Reconhece-se a conveniência do planejamento ascendente com envolvimento de profissionais e de usuários. Entretanto, não há ainda métodos seguros para articular participação horizontal da base com a preservação dos objetivos primordiais do SUS. Como combinar democratização institucional com capacidade operacional e, portanto, com algum grau de centralização vertical, sem o qual os estabelecimentos se perderiam em discussões intermináveis ou em particularismos? Como propiciar independência e autonomia para cada equipe, sem que se perca o sentido de rede de compromissos, sem que se perca a noção de sistema, ou sem que seja comprometida a diretriz da integralidade da atenção? Como assegurar um diálogo (ou um agir comunicativo - Habermas (1989)) entre usuários e técnicos? Como diminuir em alguns graus a alienação ou a burocratização atual mente verificada entre os servidores públicos? Como motivá-los, como ampliar sua capacidade de reflexão e auto-estima? Como articular autonomia e criatividade com responsabilidade profissional? 
A Teoria Geral da Administração, o taylorismo em particular, coloca-se a tarefa de administrar pessoas como se elas fossem instrumentos, coisas ou recursos destituídos de vontade ou de projeto próprio. Faz parte da cultura tradicional da maioria das Escolas da Administração o objetivo explícito de disciplinar o trabalhador, quebrar-lhe o orgulho, a autonomia e a iniciativa crítica. Delegando a padrões, normas e programas a função de operar o trabalho cotidiano daqueles encarregados de executar ações. Algumas Escolas apostaram mais em controles disci plinares para realizar este intento, bastaria-Ihes a domesticação do comportamento dos trabalhadores; outras, entretanto, mais modernas e com pensamento mais estratégico, inventaram modos para modificar a subjetividade dos sujeitos, ganhar-Ihes a alma. Porém, nenhuma destas correntes investe na produção de sujeitos dotados, ao mesmo tempo, de autonomia e de capacidade para contratar compromissos com outros (Taylor, 1960; Fayol, 1960; Motta, 1987; Campos, 1992a).

No Brasil, desde os anos setenta, há todo um movimento voltado para estimular a democratização dos serviços públicos de saúde. Participação comunitária, conselhos de saúde para permitir a gestão tripartite, com usuários, trabalhadores e prestadores, são diversas experiências interessantes, porém, exceto no que se refere à oficialização dos Conselhos e Conferências de Saúde, ainda não se encontrou modo de institucionalizar todas estas diretivas democratizantes. No dia-a-dia os serviços ainda são governados segundo diferentes variações do taylorismo. Passa-se como se a democracia acabasse nos Conselhos de Saúde ou nas Oficinas de Planejamento, daí para frente operaria lógica tradicional de gerência: poder centralizado em chefes, controle direto sobre a realização de procedimentos técnicos (produtividade médica, etc) e sobre o comportamento formal de funcionários (cumprimento de horário, relatórios, etc), elaboração centralizada de programas e de normas reguladoras do atendimento, e quase ausência de comunicação tanto entre serviços em relação horizontal de poder, quanto entre os distintos níveis hierárquicos.

Em algumas experiências, graças a utilização de variantes do Planejamento Estratégico Situacional, vive-se momentos de participação. Momentos fundamentais, mas que não chegam a modificar o sistema de gestão dos serviços de saúde: a democracia começa e termina em Oficinas de Planejamento, ou deTerritorialização, etc (Kadt \& Tasca, 1993; Cecílio, 1994; Teixeira \& Melo, 1995).
O que se pretende descrever aqui é um Método de Gestão que, apoiando-se em toda esta tradição, almeje mais do que adaptar e moldar Sujeitos. Na realidade, realizar um duplo trabaIho. Por um lado, assegurar o cumprimento do objetivo primário de cada organização - produzir saúde, educar, etc -; e por outro, ao mesmo tempo, permitir e estimular os trabalhadores a ampliar sua capacidade de reflexão, de co-gestão e, em decorrência, de realização profissional e pessoal.

A velha utopia grega da democracia direta dos cidadãos agora encarnada em instituições concretas inseridas em uma sociedade profundamente contraditória, injusta e desigual. Criar espaços de democracia ampliada, processos produtores de sujeitos-cidadãos, grupos capazes de impor resistência às determinações adversas do meio. Equipes capazes de lidar com os saberes estruturados sem permanecer presas em suas cadeias de controle fundamentalista (Campos, 1992 e 1998). Novas e velhas utopias...

Inventando uma nova geometria

e um novo funcionamento para

as organizações de saúde

Um primeiro passo na criação deste novo Método foi sugerir a modificação dos Organogramas dos serviços de saúde, em geral, inspirados no fayolismo e no taylorismo, criando 'Unidades de Produção'. Extinguir os antigos departamentos e seções recortadas segundo profissões, e criar outras Unidades mais conforme as lógicas específicas de cada processo de trabalho. Todos os profissionais envolvidos com um mesmo tipo de trabalho, com um determinado produto ou objetivo identificável, passariam a compor uma Unidade de Produção, ou seja, cada um destes novos departamentos ou serviços seriam compostos por uma Equipe multiprofissional. Todos envolvidos com saúde da criança, em um posto de saúde ou em um hospital, formariam a Unidade de Atenção à Criança, por exemplo. Todos envolvidos com administração financeira em um hospital constituiriam uma Unidade de Administração Financeira; outros responsáveis pela manutenção, limpeza e conservação conformariam uma Unidade com estes objetivos. Recomenda-se, contudo, que o número de Unidades de Produção das áreas denominadas "meio", nunca exceda aquelas, explicitamente e diretamente, encarregadas de executar tarefas "fim" da Organização (práticas de atenção à saúde). 
O desenho final de cada serviço - a maneira de recortar a Organização em Unidades, quantas Unidades criar e qual os limites e relações entre elas, etc - já seria uma primeira etapa do processo de gestão participativa: ou seja, seriam os próprios trabalhadores de cada serviço, que a partir destas orientações gerais, comporiam o novo Organograma. Para testálo durante algum tempo, avaliá-lo em funcionamento e depois ir estabelecendo as correções devidas. Organograma mutante, portanto. Sempre sujeito a reformulações, porque, de antemão, saber-se-ia e admitir-se-ia, em princípio, a sua imperfei ção.

Cada Unidade de Produção teria um único Coordenador e elaboraria um Projeto de TrabaIho. Para isto operariam segundo um princípio de funcionamento, ao mesmo tempo, democrático mas também produtor de compromissos e de responsabilidades muito bem definidas. Todos os participantes destes coletivos multiprofissionais comporiam um Colegiado para cada uma destas Unidades de Produção. Colegiado encarregado de elaborar diretrizes, metas e programas de trabalho; avaliando-os periodicamente. Ao Coordenador caberia o papel de direção executiva, implementando decisões do Colegiado da Unidade e tomando decisões imprevistas, conforme a dinâmica dos acontecimentos, mas sempre apoiando-se em diretrizes anteriormente definidas pelo coletivo. Outra função do dirigente (Coordenador) seria funcionar como um dos elos de comunicação com o exterior, estabelecer contatos com outras Unidades, com a direção-geral do serviço, com usuários, etc.

Para viabilizar este novo estilo de trabalho haveria que se alterar a cultura organizacional. Para isto, recomendava-se facilitar o acesso de todos às informações fundamentais e criar horários para encontros periódicos do coletivo em cada uma destas Unidades de Produção (em geral, não mais do que $10 \%$ da jornada de trabalho). Escolher um tempo para reuniões ordinárias dentro da período normal de trabaIho, ou seja, o planejamento e a reflexão fazendo parte do processo habitual de trabalho. Nestes espaços se discutiriam necessidades de saúde, divisão de tarefas e papéis de cada um, para, em seguida, elaborarem-se planos, modelos de atenção, programas e metas.

Cada Equipe seria estimulada a reconstruir model os ou programações recomendadas ou experimentadas em outras localidades, envolvendo a mai oria de trabalhadores com a construção de uma nova Obra. Um modo de fazer as coisas com o qual os trabalhadores se identificassem e que, ao mesmo tempo, cumprisse os compromissos daquela Unidade, daquele serviço, ou seja, atendesse a alguma demanda social, ou seja, produzisse valores de uso. Realizar uma mistura, resultado aqui seria uma mescla de determinados Produtos (socialmente necessários) com uma Obra (criação singular).

Transcrever estas metas em indicadores e fazer com que estes indicadores funcionassem como analisadores do trabalho, abrindo vislumbres críticos sobre o modo anterior de operar. Durante esta elaboração haveria que se considerar dados externos e internos à equipe: tomar as diretrizes e recomendações dos níveis mais centrais do sistema, auscultar interesses e demandas da clientela e debater com outras experiências, com outros modos de enfrentamento de problemas semel hantes aos de responsabilidade daquela Unidade.

Recomendava-se, também a instituição de Supervisão Matricial que aumentasse a abertura destas Unidades para o externo. Supervisão não conforme a concepção taylorista - alguém que controla e fiscaliza o cumprimento de normas -, mas quase com o sentido que lhe era atribuído pela Saúde Mental: supervisor como agente externo que se reúne com a equipe para instituir processos de reflexão crítica e de educação permanente. Então, Supervisor como apoiador e agenciador de mudanças, al guém que ajudasse na identificação e no enfrentamento de problemas. Este trabalho de apoio poderia assumir tanto um caráter mais técnico especialistas em enfermagem, em pediatria, etc, ajudando, orientando várias equipes em que houvesse este tipo de responsabilidade -, ou mais um de instrumentalizador de processos de mudança. Neste segundo caso, um agenciador e estimulador da capacidade de análise e de participação do grupo na gestão, uma combinação das funções típicas de um analista de grupo com as de um assessor de planejamento. De qualquer modo, estes Supervisores não teriam linha de comando dentro das Unidades de Produção. Somente a Direção geral ou o Coordenador, ou os próprios Colegiados tomariam deliberações a serem acatadas por todos.

Conforme sugeria a Qualidade Total (Campos, 1992a), recomenda-se aqui também diminuir o número e o poder de influência das direções intermediárias. A diferença estaria em que, neste novo Modelo, aquelas funções, antes atribuídas às direções intermediárias, seriam substituídas ou pelo sistema colegiado de direção, ou pelo sistema de Supervisão Matricial - exemplo, a antiga chefia de todos os serviços de enfermagem de um hospital, caso seja de reconhecida competência técnica, passaria a exercer a função de Supervisão Matricial de 
todas as Unidades em que o trabalho de enfermagem acontecesse.

Haveria também grandes modificações nos sistema de Direção Geral das Organizações. O Diretor-geral, ou Superintendente e seus assessores teriam uma função executiva semelhante àquela descrita para os Coordenadores de cada Unidade de Produção, e comporiam, junto com todos os Coordenadores de cada uma das Unidade de Produção, um Colegiado Geral de Direção. Com reuniões periódicas, este grupo seria a instância máxima de deliberação do estabelecimento: um Colegiado composto pela Direção-geral, assessores e por cada um dos Coordenadores das Unidades de produção e, eventualmente, alguns dos Supervisores. Um espaço para elaboração e compatibilização das demandas e projetos de cada Unidade de Produção, mas também correia de transmissão e de elaboração de diretrizes do sistema de saúde, dos projetos e prioridades provenientes ou de outras instâncias de Governo ou oriundas dos Conselhos de Saúde em que há participação de usuários.

Este Colegiado Geral cumpriria uma função integradora, tentando articular aquilo que a descentralização do poder tenderia a opor ou a fragmentar (Figura 1).

\section{O método de gestão colegiado \\ e a co-gestão}

Diferentemente dos analistas institucionais, Lapassade (1989), Deleuze \& Guattari (1976), sugere-se que o objetivo da Autogestão não somente seria inatingível (irrealizável), como seria também indesejável. Porque implicaria em descompromisso com o interesse alheio, e poderia redundar em autogoverno com características exclusivistas e excludentes. Por isto, elegeu-se como conceito diretor aquele de Cogestão, ou de Co-governo, ou seja, todos decidindo, porém decidindo tendo em vista outras

Figura 1

Nova geometria para instituições democratizadas.

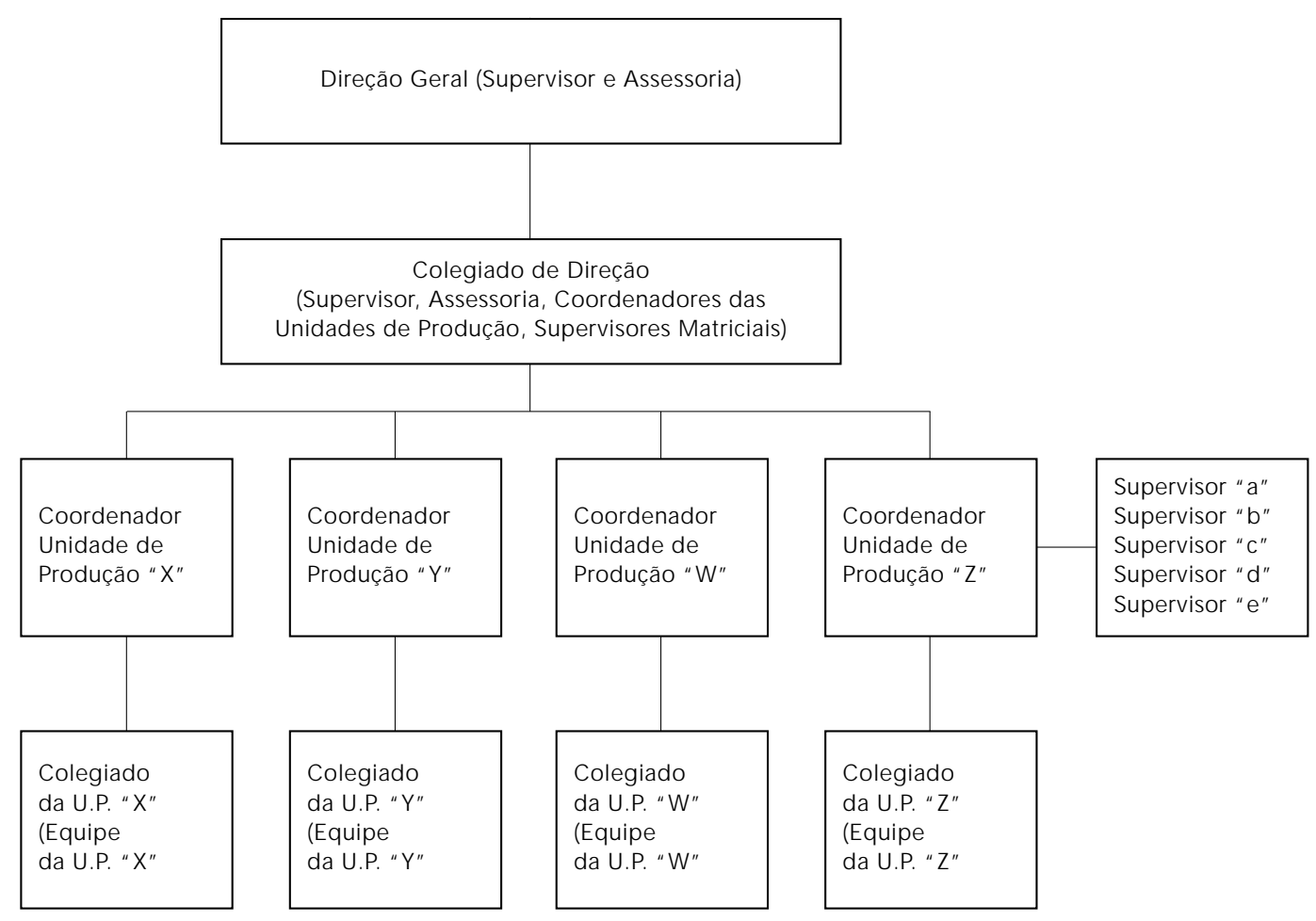

Nota: Na linha vertical, colocam-se a direção geral, coordenadores das unidades de produção (U.P.) e os colegiados respectivos; na horizontal, representado por linhas interrompidas, sentido matricial, estariam os supervisores, bem como alguns trabalhadores que realizem tarefas em mais de uma unidade de produção (U.P.). 
instâncias, deliberar entre interesses em pugna, em negociação permanente, em discussão e em recomposição com outros desejos, com outros interesses e com outras instâncias de poder. Diferente da Autogestão, o conceito de Co-gestão partiria do princípio de que não haveria poder nem dominação absolutos, mas sempre relativos e em relação com outros graus de poder e de dominação.

O mesmo raciocínio vale para as possibilidades de liberdade ou de autonomia. Liberdade e autonomia também não existem em absoluto, ao contrário do que afirma o pensamento idealistas. Liberdade e autonomia de Sujeitos concretos somente existem em coeficientes, ou em cotas. Não há liberdade ou autonomia total. Tampouco haveria dominação ou determinação total, sempre sobraria algum espaço para resistência, para atenuar, para ludibriar ou até para vencer imposições externas opressivas. Assim, o Método de Gestão colegiada baseia-se, não na idéia de autogestão, mas no conceito de Co-gestão. Todos participam do governo, nas ninguém decide sozinho ou isolado ou em lugar dos outros.

As funções de dirigente ou de liderança não estariam eliminadas neste modo de governar, somente não assumiriam um caráter exclusivo e unipessoal. De um dirigente-titular, supostosabido e todo-poderoso, saltar-se-ia para um Colegiado composto por diretores e coordenadores de cada uma das Unidades de Produção. No entanto, cada um destes diretores cumpriria funções executivas, operacionais, de controle, cabendo-Ihes tanto assegurar o cumprimento das deliberações, quanto tomar decisões que os espaços colegiados não houvessem trabalhado.

Estes Colegiados não substituem ou tampouco deveriam se confundir com os ConseIhos de Saúde com participação majoritária de usuários. Eles têm função operacional, interna às organizações e aos estabelecimentos e estariam subordinadas aos Conselhos de Saúde. Este sistema não asseguraria por si só a participação ou o envolvimento de usuários. Por outro lado, também os Consel hos Municipais previstos na legislação, em geral, se postam muito distante da gestão cotidiana de cada serviço de saúde. Para atenuar esta separação da clientela e de outros setores da sociedade civil do funcionamento cotidiano dos serviços, imaginouse uma rede de dispositivos complementares, todos voltados para aumentar a influência do usuário tanto no dia-a-dia quanto nas grandes decisões do sistema. Para isto sugere-se desde a realização periódica de Assembléias de Usuários em que o Colegiado de Direção estivesse obrigatoriamente presente, até a constituição de Conselhos Locais por cada distrito ou até mesmo cada serviço de saúde. Estes Conselhos Locais funcionariam por representação, obedecendo a mesma lógica e composição previstas para os Conselhos Municipais.

No entanto, faziam-se também necessários mecanismos que dessem capilaridade a este sistema de participação. Neste caso, o principal dispositivo para aumentar o poder do usuário no cotidiano era a recomendação de que os serviços de saúde voltassem a funcionar também segundo uma lógica de delegação individual de responsabilidade. Não deveria haver, quer em modalidades ambulatoriais ou de internação, nenhum paciente sem um profissional escolhido ou designado para ser sua Referência. Valorizava-se, portanto, o Padrão de Vínculo estabelecido entre trabalhadores e usuários, não somente em termos genéricos ou coletivos, mas também em sua dimensão individual. Cada técnico ou cada mini-equipe teriam responsabilidade integral sobre determinado número de casos. Os demais trabal hadores os apoiaram mediante ações articulados em movimentos matriciais: inter-consultas, ações específicas ofertadas para clientes ligados a distintos Profissionais de Referência, etc. Neste caso, a busca de padrões de vínculo mais qualificados, explícitos e duradouros, além de vantagens de ordem política, a de propiciar maior controle do usuário sobre os técnicos; ou de ordem gerencial, a de explicitar graus de compromisso e de competência de cada trabaIhador; contribuiria também para aumentar a eficácia do trabalho clínico e de reabilitação. Sabe-se que não há clínica eficaz sem personalização e contextualização dos projetos ou programas terapêuticos.

Esta nova Metodologia de Gestão imaginase potente para lidar com várias polaridades que operam em caráter quase que permanente nos serviços de saúde. No caso, optou-se por considerar que estas contradições nunca teriam sínteses definitivas. Ao contrário, toda solução seria provisória e recolocaria o antigo conflito dentro de novos patamares, mas nunca os eliminaria, apenas os reporia com novas características. Assim, imaginou-se uma Metodologia de Gestão capaz de combinar coeficientes de democracia direta (participativa) com a preservação de algum grau de unidade em torno daqueles objetivos primários de cada instituição; ou seja, combinar interesses dos usuários com outros mais próximos aos trabaIhadores. Imaginou-se um Método que mesclasse participação com busca de produtividadee de compromisso; mas, sobretudo, antevia- 
se a possibilidade de montagem de uma máquina organizacional que fosse, ao mesmo tempo, terapêutica e pedagógica para os trabalhadores - no sentido, de permitir seu crescimento pessoal e coletivo de forma contínua e progressiva - e também produtora de saúde ou de educação para o público.

Para este fim, tratou-se de combinar diretrizes da Análise Institucional (autogestão e auto-análise dos trabalhadores - Baremblit, 1992; Lapassade, 1989) com outras típicas de qualquer empresa pública, ou seja, com a necessidade de atender demandas sociais segundo certos padrões definidos pela sociedade e não somente por aquele grupo de "autogestores". Por isto, falava-se em coeficientes, em graus de autonomia ou de Co-gestão. Governar junto, não somente ser governado ou imaginar o delírio de governar-se ignorando as imposições da realidade. Este processo de negociação permanente do Sujeito com seu entorno foi teorizada tanto por Freud (princípio de realidade), quanto por Gramsci e Sartre (o primeiro criou a idéia de composição de interesses e de projetos para conformação de “Blocos Históricos"; e o segundo, a noção de "Grupos Sujeitos" (Freud, 1976; Gramsci, 1976, 1978; Sartre, 1963).

Neste sentido, considera-se que sempre haverá antagonismos intermináveis entre a Missão Básica dos Sistemas de Saúde e os Interesses Corporativos de suas várias categorias profissionais. Haverá sempre conflitos entre Diretores, Coordenadores das Unidades e seus Colegiados; e desentendimentos entre médicos, enfermeiros, técnicos e usuários continuam existindo. Mas, e então? Mais; haverá constantes disputas em torno de modelos e programas de atenção, divisão de trabalho e atribuição de responsabilidades! Mas, e então?

Na verdade o Método nunca se propôs a resolver estes conflitos e muito menos a eliminar estas contradições. Ao contrário, tratar-se-ia de, ao admitir a inevitável existência destas polaridades, e de se criar espaços onde pudessem ser explicitadas e trabalhadas, considerandose, sempre, os vários interesses e, portanto, as várias racionalidades envolvidas.

Na verdade, sugere-se aqui uma máquina gerencial instituinte. Contradição em termos: máquina e gestão se referem ao estabelecido, à reprodução do instituído; e o novo Método as querendo instituinte! Uma máquina supostamente co-produtora de sujeitos aptos para o exercício da liberdade, para assumir os riscos e o prazer da criação, mas também preparados para contratar compromissos, para respeitar a missão primária da instituição em que estivessem inseridos.
Lendo Heráclito, Hegel, Marx e Gramsci é possível aprender alguma coisa sobre a lógica dialética, e não é muito difícil reformular algumas destas ferramentas conceituais para repensar a maioria de nossas práticas voltadas para o controle social e dominação. Realizar este esforço modifica a visão de mundo de um coletivo. Como escreveu Pichon-Rivière, “... ao uso instrumental da lógica formal acrescentou-seo da lógica dialética eo da noção de conflito, em que os termos não se excluem, mas estabelecem uma continui dade genéti ca sobre a base de sínteses sucessivas" Pichon-Rivière (1988:24). E ao que valeria acrescentar, sínteses sucessivas, sim, porém provisórias, porque instauradoras de outros conflitos estimuladores de outros movimentos. Não é simples acostumar-se com a idéia da convivência de termos conflitantes, e menos ainda o seria lidar com estes dilaceramentos na prática, claro-escuro, todo o tempo, lusco-fusco, certo-certo e certo-errado e errado-errado, todo o tempo, misturados, juntos. Descobrir a importância e a necessidade de se aprender também com o pólo que se deseja superar. Aprender a aprender com o objeto submetido a crítica, não há sabedoria sem esta dialética da aproximação e do distanciamento dos objetos ou fenômenos ou sujeitos com os quais interagimos. Descobrir ainda que o pólo negado nunca seria absolutamente suprimido, mas, sim, em caso de sucesso, incorporado à síntese vitoriosa.

Assim, sugere-se uma máquina gerencial dialética, uma mecanismo capaz de lidar com o conflito social básico à instituição de qualquer sociedade, ou seja, com o conflito entre desejos individuais e necessi dades sociais. Um eterno jogo, um espaço que obrigue trabalhadores, dirigentes e usuários a considerar interesses e falas dos outros autores. Uma máquina que assegure tanto possibilidades de participação e que, portanto, produza distribuições mais equilibradas de poder, como também garanta objetividade e praticidade ao funcionamento do estabelecimento. Discussão, negociação, explicitação de diferenças; porém sempre seguidas de sínteses operativas a serem colocadas em prática pelos trabalhadores. E que a maioria aprenda algo com o processo, educação continuada em ato.

Resumindo, poder-se-ia enumerar parte das vantagens potenciais resultantes do funcionamento desta nova Metodologia:

- melhoria no grau de envolvimento e de compromisso das Equipes com a Instituição como um todo e, particularmente, com os Projetos que elas foram ajudando a inventar. A maior parte do pessoal sentindo-se criadora dos Modelos testados e, com isto, potenciali- 
zando-se um aumento da sua taxa de felicidade e de realização profissional. A maioria das Equipes se caracterizando por um amor explícito ao trabalho executado, sentimento, hoje em dia, raro no setor público e mesmo no privado. Orgulho profissional, compromisso e dedicação ao paciente e às reformas que elas vêm inventando;

- criação de um sistema informal de Educação Continuada do estilo paidéia (educação integral), graças a multiplicação dos espaços onde se trocam informação, se intercambiam saberes e se discutem problemas: oficinas de planejamento, discussão de casos, elaboração

\section{Referências}

BAREMBLIT, G., 1992. Compêndio de Análise Institucional. São Paulo: Rosa do Ventos.

BRAVERM AN, H., 1981. Trabal ho e Capital Monopolista: A Degradação do Trabal ho no Século XX. São Paulo: Pioneira.

CAMPOS, V. F., 1992a. Controle de Qualidade Total. Belo Horizonte: Fundação Christiano Ottoni/ Universidade Federal de Minas Gerais.

CAM POS, G. W. S., 1992b. Reforma da Reforma: Repensando a Saúde. São Paulo: Hucitec.

CAMPOS, G. W. S., 1998. Subjetividade e administração de pessoal: considerações sobre modos de gerenciar trabalho em equipes de saúde. In: Agir em Saúde (E. E. Merhy \& R. Onocko, orgs.), pp. 229-266, São Paulo: Hucitec.

CECÍLIO, L. C. O., 1994. Inventando a Mudança na Saúde. São Paulo: Hucitec.

DELEUZE, G. \& GUATTARI, F., 1976. O Anti-Édipo: Esquizofrenia e Capital ismo. Rio de Janeiro: Imago.

FAYOL, H., 1960. Administração Geral e Industrial. São Paulo: Atlas.

FREUD, S., 1976. Obras Completas. Vol. XXII. Rio de Janeiro: Imago.

GORZ, A., 1982. Adeus ao Proletariado. Rio de Janeiro: Forense.

GRAM SCI, A., 1976. Maquiavel, a Política e o Estado Moderno. Rio de Janeiro: Civilização Brasileira.

GRAMSCI, A., 1978. Concepção Dialética da História. Rio de Janeiro: Civilização Brasileira.

HABERMAS, J., 1989. Consciência Moral eAgir Comunicativo. Rio de Janeiro: Tempo Brasileiro. conjunta de projetos terapêuticos individuais ou de programas coletivos de atenção. Potencializando-se um amadurecimento da maioria do pessoal para lidar tanto com aspectos técnicos, quanto políticos, humanos ou éticos, ou seja, crescimento da capacidade de ouvir e expor críticas, para aceitar derrotas e estabelecer negociações e consensos;

- e, finalmente, melhoria sensível da relação Equipes de Saúde com os usuários e seus familiares, graças a instituição de sistemas de referência com responsabilização e cuidados mais bem definidos e micro-sistemas de controle social.
KADT, E. \& TASCA, R., 1993. Promovendo a Eqüidade: Um Novo Enfoque com Base no Setor Saúde. São Paulo: Hucitec.

LAPASSADE, G., 1989. Grupos, Organizações e Instituições. Rio de Janeiro: Francisco Alves.

MOTTA, F. C. P., 1987. Teoria Geral da Administração. São Paulo: Livraria Pioneira.

OFFE, C., 1989. Trabal ho e Sociedade: Problemas Estruturais e Perspectivas para o Futuro da Sociedade do Trabalho. Rio de Janeiro: Tempo Brasileiro.

PICHON-RIVIÈRE, E., 1988. O Processo Grupal. São Paulo: Martins Fontes.

RAGO, L. M. \& MOREIRA, E. F. P., 1984. O queéTaylorismo. São Paulo: Brasiliense.

ROTELLI, F., 1990. A instituição inventada. In: Desinstitucionalização (F. Nicácio, org.), pp. 13-32, São Paulo: Hucitec.

SARTRE, J. P., 1963. Crítica de la Razón Dialética. Buenos Aires: Losada.

TAYLOR, W., 1960. Princípios de Administração Científica. São Paulo: Atlas.

TEIXEIRA, C. F. \& MELO, C., 1995. Construindo Distritos Sanitários. São Paulo: Hucitec/Cooperação Italiana em Saúde.

TESTA, M., 1993. Pensar en Salud. Buenos Aires: Lugar. TRAGTEM BERG, M., 1972. Burocracia e Ideologia. Tese de Doutorado, São Paulo: Departamento de Ciências Sociais, Universidade de São Paulo.

TRAGTEMBERG, M., 1980. Administração, Poder e Ideologia. São Paulo: Moraes. 